\title{
Hydrogen Sulfide Prevents Advanced Glycation End-Products Induced Activation of the Epithelial Sodium Channel
}

\author{
Qiushi Wang, ${ }^{1}$ Binlin Song, ${ }^{1}$ Shuai Jiang, ${ }^{1}$ Chen Liang, ${ }^{1}$ Xiao Chen, ${ }^{1}$ Jing Shi, ${ }^{1}$ Xinyuan Li, \\ Yingying Sun, ${ }^{1}$ Mingming Wu, ${ }^{1}$ Dan Zhao, ${ }^{1}$ Zhi-Ren Zhang, ${ }^{1}$ and He-Ping $\mathrm{Ma}^{2}$ \\ ${ }^{1}$ Departments of Clinical Pharmacy and Cardiology, Institute of Clinical Pharmacy, The Second Affiliated Hospital, \\ Harbin Medical University, Key Laboratories of Education Ministry for Myocardial Ischemia Mechanism and Treatment, \\ Harbin 150086, China \\ ${ }^{2}$ Department of Physiology, Emory University School of Medicine, Atlanta, GA 30322, USA
}

Correspondence should be addressed to Zhi-Ren Zhang; zhirenz@yahoo.com and He-Ping Ma; heping.ma@emory.edu

Received 19 November 2014; Accepted 26 December 2014

Academic Editor: Guangdong Yang

Copyright (C) 2015 Qiushi Wang et al. This is an open access article distributed under the Creative Commons Attribution License, which permits unrestricted use, distribution, and reproduction in any medium, provided the original work is properly cited.

\begin{abstract}
Advanced glycation end-products (AGEs) are complex and heterogeneous compounds implicated in diabetes. Sodium reabsorption through the epithelial sodium channel $(\mathrm{ENaC})$ at the distal nephron plays an important role in diabetic hypertension. Here, we report that $\mathrm{H}_{2} \mathrm{~S}$ antagonizes AGEs-induced $\mathrm{ENaC}$ activation in $\mathrm{A} 6$ cells. ENaC open probability $\left(P_{\mathrm{O}}\right)$ in $\mathrm{A} 6$ cells was significantly increased by exogenous AGEs and that this AGEs-induced ENaC activity was abolished by NaHS (a donor of $\mathrm{H}_{2} \mathrm{~S}$ ) and TEMPOL. Incubating A6 cells with the catalase inhibitor 3-aminotriazole (3-AT) mimicked the effects of AGEs on ENaC activity, but did not induce any additive effect. We found that the expression levels of catalase were significantly reduced by AGEs and both AGEs and 3AT facilitated ROS uptake in A6 cells, which were significantly inhibited by NaHS. The specific PTEN and PI3K inhibitors, BPV (pic) and LY294002, influence ENaC activity in AGEs-pretreated A6 cells. Moreover, after removal of AGEs from AGEs-pretreated A6 cells for 72 hours, ENaC $P_{O}$ remained at a high level, suggesting that an AGEs-related "metabolic memory" may be involved in sodium homeostasis. Our data, for the first time, show that $\mathrm{H}_{2} \mathrm{~S}$ prevents AGEs-induced ENaC activation by targeting the ROS/PI3K/PTEN pathway.
\end{abstract}

\section{Introduction}

Advanced glycation end-products (AGEs) are modified proteins or lipids that become nonenzymatically glycated and oxidized after contacting aldose sugars and polypeptides. High levels of glucose react with proteins to form adduct AGEs in diabetes mellitus [1]. Increasing evidence suggests that AGEs play an important role in the development of diabetic nephropathy. Typically, proteins after being directly cross-linked to AGEs can change cellular structure and function or may interact with a combination of different cell surface receptors $[1,2]$. The long-term progression of diabetic complications in kidney could be a metabolic memory phenomenon. In other words, even after hyperglycemia is efficiently controlled previous exposure of the target cells to high glucose (HG) may still cause the persistence of its deleterious effects. Hypertension is a major complication in diabetes and is the cause of the increasing morbidity and mortality in diabetic patients. Hypertension alone accounts for nearly $85 \%$ of cardiovascular disease (CVD) risk factors. Since diabetic patients tend to have higher blood pressure than nondiabetic patients [3], after becoming hypertensive they should have even higher risk for CVD. Therefore, control of the development of hypertension in diabetic patients is very critical for preventing CVD. Recent studies have demonstrated that AGEs are upregulated in hypertensive diabetic subjects, particularly in distal nephron cells [4]. AGE accumulation mediates proliferation, migration, metabolic memory, and inflammatory gene expression in the distal nephron, which is thought to accelerate hypertension development in diabetes [5]. However, the detailed mechanisms underlying hypertension in diabetic patients are not fully understood. 
The epithelial sodium channel $(\mathrm{ENaC})$ mediates $\mathrm{Na}^{+}$ absorption across epithelial cells in the kidney collecting duct, lung, distal colon, and sweat duct. $\mathrm{Na}^{+}$transport is critical for $\mathrm{Na}^{+}$homeostasis and thus plays a vital role in maintaining salt balance and systemic blood pressure. ENaC excess activation causes hypertension, as seen in Liddle's syndrome [6]. In type 1 and type 2 diabetic animal models, the expression levels of $\mathrm{ENaC}$ were increased in cortical collecting duct cells. Cultured with AGEs, ENaC was increased at both mRNA and protein levels in mouse CCD cells [7]. Therefore, it is very possible that AGEs may be involved in the development of hypertension in diabetes, at least, in part, by stimulating $\mathrm{ENaC}$ function.

Hydrogen sulfide $\left(\mathrm{H}_{2} \mathrm{~S}\right)$ is an important intercellular gaseous messenger molecule that regulates multiple physiological and pathological processes. Accumulating evidence has shown that $\mathrm{H}_{2} \mathrm{~S}$ protects against a number of organ injuries. One of the primary mechanisms of $\mathrm{H}_{2} \mathrm{~S}$ protection is antioxidation, as it either enhances reduced glutathione (GSH, a major cellular antioxidant) [8] or directly scavenges superoxide [9], $\mathrm{H}_{2} \mathrm{O}_{2}$ [10], and peroxynitrite [11] to suppress oxidative stress. Our previous studies suggest that $\mathrm{H}_{2} \mathrm{~S}$ could protect $\mathrm{H}_{2} \mathrm{O}_{2}$-induced ENaC activity in A6 cells [12]. Therefore, we hypothesized that AGEs might elevate ENaC activity and that $\mathrm{H}_{2} \mathrm{~S}$ might protect against this elevation. The present study shows that $\mathrm{H}_{2} \mathrm{~S}$ prevents AGEs-induced ENaC activation by targeting the ROS/PI3K/PTEN pathway.

\section{Materials and Methods}

2.1. Cell Culture. A6 cells are an established renal cell line derived from the Xenopus laevis distal nephron segment, which is an appropriate cell model for studying ENaC [12]. A6 cells were purchased from American Type Culture Collection (Rockville, MD, USA) and grown in the medium consisting of 3 parts of DMEM/F-12 (1:1) medium (Gibco, USA), 1 part of $\mathrm{H}_{2} \mathrm{O}, 15 \mathrm{mMNaHCO}_{3}$ (total $\mathrm{Na}^{+}=101 \mathrm{mM}$ ), $2 \mathrm{mM}$ L-glutamine, $10 \%$ fetal bovine serum (Invitrogen, USA), 25 units/mL penicillin, and 25 units/mL streptomycin, as previously described [13]. A6 cells were cultured in plastic flasks in the presence of $1 \mu \mathrm{M}$ aldosterone at $26^{\circ} \mathrm{C}$ and $4 \% \mathrm{CO}_{2}$. After the cells reached $70 \%$ confluence, they were subcultured on polyester membranes of Transwell inserts (Corning Costar Co, USA) for confocal microscopy or Snapwell inserts (Corning Costar Co, USA) for cell-attached patch-clamp analysis. To allow for polarization, cells were cultured for at least 2 to 3 weeks before performing experiments.

2.2. Patch-Clamp Recording. ENaC single-channel currents were recorded using a cell-attached patch-clamp configuration with an Axopatch-200B amplifier (Axon Instruments, USA) as described previously $[14,15]$. A6 cells were thoroughly washed with $\mathrm{NaCl}$ solution containing (in $\mathrm{mM}$ ) $100 \mathrm{NaCl}, 3.4 \mathrm{KCl}, 1 \mathrm{CaCl}_{2}, 1 \mathrm{MgCl}_{2}$, and $10 \mathrm{HEPES}$, adjusted to $\mathrm{pH} 7.4$ with $\mathrm{NaOH}$. This $\mathrm{NaCl}$ solution was used as bath solution for recordings and used to fill the electrodes. The reagents were added to the bath solution from either basolateral side or apical side. Borosilicate glass electrodes had tip resistance of 7-10 M $\Omega$ when filled with $\mathrm{NaCl}$ solution. Experiments were conducted at room temperature $\left(22-25^{\circ} \mathrm{C}\right)$. The data were acquired by application of $0 \mathrm{mV}$ pipette potential and were sampled at $5 \mathrm{kHz}$ and low-pass filtered at $1 \mathrm{kHz}$ with Clampex 10.2 software (Molecular Devices, Sunnyvale, CA, USA). Prior to analysis, the single-channel traces were further filtered at $30 \mathrm{~Hz}$. The total number of functional channels in the patch was determined by observing the number of peaks detected on the current amplitude histograms during at least $10 \mathrm{~min}$ recording period. The open probability $\left(P_{\mathrm{O}}\right)$ of $\mathrm{ENaC}$ before and after chemical application was calculated with Clampfit 10.2 (Molecular Devices, Sunnyvale, CA, USA). Control ENaC activity was recorded for 2 min after forming the cell-attached mode and $\mathrm{ENaC}$ activity stabilized. A single patch was typically recorded for at least $30 \mathrm{~min}$ before any experimental manipulation.

2.3. Confocal Laser Scanning Microscopy Analysis. Studies were performed using confocal microscopy (Olympus Fluoview 1000, Japan) as previously described $[12,13,16]$. A6 cells were washed twice with $\mathrm{NaCl}$ solution prior to the performance of any experiments. Immediately following experimental manipulation, the polyester membrane support was quickly excised and mounted on a glass slide with a drop of $\mathrm{NaCl}$ solution to keep the cells alive. A6 cells grown on Transwell inserts were loaded with $2.5 \mu \mathrm{M} 5$ (and-6)-carboxy-2', $7^{\prime}$-dichlorodihydrofluorescein diacetate (carboxy- $\mathrm{H}_{2}$ DCFDA), a membrane-permeable ROS-sensitive fluorescent probe (Invitrogen, USA) that becomes fluorescent when oxidized. Prior to exogenous AGEs or 3-AT application, A6 cells were treated with an iron chelator, $50 \mu \mathrm{M}$ $2,2^{\prime}$-dipyridyl for $3 \mathrm{~min}$ [17]. Labeled cells were washed twice in modified DPBS before confocal microscopy analysis. ROS levels were measured by fluorescence intensity.

2.4. Western Blotting. A6 cells were cultured as described above. Cell lysates $(100 \mu \mathrm{g})$ were loaded and electrophoresed on 10\% SDS-polyacrylamide gels for 60-90 min. Gels were blotted onto polyvinylidene fluoride (PVDF) membranes for $1.5 \mathrm{~h}$ at $200 \mathrm{~mA}$. After $1 \mathrm{~h}$ of blocking in $5 \%$ nonfat dry milk in phosphate-buffered saline (PBS), PVDF membranes were incubated with a rabbit polyclonal primary antibody $(1: 2,000)$ against catalase (Abcam, ab16731) overnight at $4^{\circ} \mathrm{C}$ and then incubated with a horseradish peroxidaseconjugated secondary antibody (Santa Cruz Biotechnology, USA, 1:5000) for $1 \mathrm{~h}$ at room temperature after four vigorous washes. Finally, blots were visualized by chemiluminescence using the ECL Plus Western blotting detection system (BioRad, USA).

2.5. Chemicals and Reagents. Unless otherwise noted, all chemicals and reagents were purchased from Sigma Aldrich (St. Louis, MO, USA). AGEs were purchased from Cell Biolabs (San Diego, USA). All solutions were premade and stored in a $-20^{\circ} \mathrm{C}$ freezer or freshly made before use.

2.6. Data Analysis. Data are presented as mean \pm S.E. Statistical analysis was performed with SigmaPlot and SigmaStat 
software (Jandel Scientific, CA, USA). Student's $t$-test was used to compare pre- and posttreatment activities. Analysis of variance (ANOVA) was used to make multiple comparisons among various treatment groups. Differences were considered statistically significant when $P<0.05$.

\section{Results}

3.1. $\mathrm{H}_{2} \mathrm{~S}$ Reverses AGEs-Induced ENaC Activity in A6 Cells. To investigate whether AGEs enhance ENaC activity, we performed cell-attached patch-clamp experiments. Because in diabetic patients AGEs are delivered to renal epithelial cells from the blood, we applied AGEs to the basolateral side of A6 cell monolayer to mimic the in vivo AGEs delivery. We compared ENaC $P_{O}$ in cell-attached patches from four experimental groups: control (basolateral incubation of A6 cells with $200 \mu \mathrm{g} / \mathrm{mL}$ BSA for $24 \mathrm{~h}$ ), AGEs (cells treated with basolateral $200 \mu \mathrm{g} / \mathrm{mL}$ AGEs for $24 \mathrm{~h}$ ), NaHS (cells treated with $0.1 \mathrm{mMNaHS}$ for $30 \mathrm{~min}$; in addition, NaHS at 0.05 , 0.1 , or $0.3 \mathrm{mM}$ does not affect cell viability [12]), and AGEs $+\mathrm{NaHS}$ (cells treated with basolateral $200 \mu \mathrm{g} / \mathrm{mL}$ AGEs for $24 \mathrm{~h}$ and then incubation with $0.1 \mathrm{mM} \mathrm{NaHS} 30 \mathrm{~min}$ ). After treatment with AGEs, ENaC $P_{\mathrm{O}}$ was significantly increased, from $0.22 \pm 0.03$ (control; $n=10$ ) to $0.50 \pm 0.03$ (AGEs; $n=10$; $P<0.01$ compared to control). Consistent with our previous studies [12], NaHS did not affect ENaC $P_{O}$ compared with control $(0.23 \pm 0.03 ; n=10 ; P>0.05)$. The AGEs-induced increase in $\mathrm{ENaC} P_{\mathrm{O}}$ was reversed by NaHS $(0.25 \pm 0.01 ; n=$ 10; $P<0.01$ compared to AGEs and $P>0.05$ compared to control) (Figure 1). These results suggest that AGEs strongly stimulate ENaC activity in A6 cells and that $\mathrm{H}_{2} \mathrm{~S}$ exerts a sufficient protective effect on AGE-induced ENaC activity.

3.2. Inhibition of Catalase Activity Mimics the Effect of AGEs on ENaC. Because AGEs potently inhibit catalase and ROS regulates $\mathrm{ENaC}[12,13,18]$, we reasoned that AGEs might stimulate $\mathrm{ENaC}$ by increasing ROS levels via inhibition of catalase. Therefore, we used a catalase inhibitor, 3-AT [19], to treat A6 cells. As shown in Figure 2(a), ENaC activity was significantly upregulated by application of $20 \mathrm{mM} 3-\mathrm{AT}$ to the basolateral bath; ENaC $P_{O}$ was increased from $0.22 \pm 0.03$ (control; $n=10)$ to $0.57 \pm 0.07(n=9 ; P<0.01$ compared to control) (Figure 2(b)). We have to note that $20 \mathrm{mM} 3-\mathrm{AT}$ led to an increase in osmolarity from $268 \pm 2 \mathrm{mOsmol} / \mathrm{kg}$ $(n=3)$ to $302 \pm 3 \mathrm{mOsmol} / \mathrm{kg}(n=3)$. However, increasing in osmolarity up to $400 \mathrm{mOsmol} / \mathrm{kg}$ (adjusted by sucrose) did not affect ENaC $P_{O}$ in A6 cells (data not shown), which suggests that the effect of 3-AT on $\mathrm{ENaC}$ is not due to changes in osmolarity. The combined application of AGEs to the basolateral bath and 3-AT to the apical bath did not further upregulate $\mathrm{ENaC}\left(P_{\mathrm{O}}=0.63 \pm 0.03 ; n=9 ; P>0.05\right.$ compared to 3 -AT alone) (Figures 2(a) and 2(b)). These results suggest that AGEs and 3-AT may activate ENaC through the same pathway associated with catalase activity and accumulation of ROS.

3.3. $\mathrm{H}_{2} \mathrm{~S}$ Attenuates Both AGEs- and 3-AT-Induced Oxidative Stress in A6 Cells. AGEs are known to inhibit catalase expression [18]. The inhibition of oxidative stress accounts for the cardioprotective effects of $\mathrm{H}_{2} \mathrm{~S}$ during ischemia/reperfusion (I/R) [20, 21]. However, it is unknown whether $\mathrm{H}_{2} \mathrm{~S}$ can reduce AGE-induced or 3-AT-induced oxidative stress in A6 cells. Therefore, we examined intracellular ROS levels with an ROS-sensitive fluorescent probe, DCF (refer to Section 2), in the presence of AGEs, AGEs + NaHS, 3-AT, or 3-AT + NaHS. Our results show that pretreatment of A6 cells with AGEs or 3-AT induced significant increase in intracellular fluorescence intensity. These results suggest that exogenous AGEs or 3-AT significantly elevated intracellular ROS in A6 cells. Furthermore, application of $0.1 \mathrm{mMNaHS}$ for $30 \mathrm{~min}$ led to a significant decrease in intracellular ROS levels, as suggested by reduced fluorescence intensity upon incubation with NaHS (Figures 3(a)-3(d); $n=7)$. Our Western blotting data show that AGEs caused a significant decrease in catalase expression in A6 cells (Figure 3(e); $n=6$ ). These results together suggest that AGEs increase intracellular ROS via inhibition of catalase and $\mathrm{H}_{2} \mathrm{~S}$ significantly attenuates AGEs and 3-AT induced ROS accumulation in A6 cells.

3.4. TEMPOL Abolishes Both AGEs- and 3-AT-Induced Activation of ENaC. 2,2,6,6-Tetramethyl-1-piperidinyloxy (TEMPOL) is a well-known scavenger used to remove ROS from the cells. To confirm the role of ROS in stimulating ENaC activity, we added $250 \mu \mathrm{M}$ TEMPOL to the basolateral bath. Our data show that even under control conditions ENaC $P_{O}$ was significantly decreased by addition of TEMPOL, from $0.30 \pm 0.03$ (before) to $0.15 \pm 0.02$ (15 min after TEMPOL) in A6 cells $(n=6 ; P<0.01)$ (Figure $4(\mathrm{a}))$. ENaC $P_{O}$ was also decreased by TEMPOL, from $0.52 \pm 0.05(n=7)$ to $0.33 \pm 0.05$ in AGEs treated cells $(n=7 ; P<0.01)$ (Figure 4(b)) or from $0.51 \pm 0.02(n=7)$ to $0.27 \pm 0.02$ in 3-AT treated cells $(n=7 ; P<0.01)$ (Figure 4(c)). These data suggest that AGEs stimulate $\mathrm{ENaC}$ in A6 cells via a pathway closely associated with altered intracellular ROS.

3.5. AGEs Elevate ENaC $P_{\mathrm{O}}$ through the PTEN and PI3K Pathways. It is known that the tumor suppressor phosphatase and tension homolog (PTEN) reduces the cellular concentration of $\mathrm{PI}(3,4,5) \mathrm{P}_{3}$ and acts as a negative regulator of PI3K signaling pathways [22]. Our previous data show that increased intracellular ROS regulates $\mathrm{ENaC}$ via increased apical $\mathrm{PI}(3,4,5) \mathrm{P}_{3}$ by affecting both PTEN and PI3K $[12,13]$. Therefore, we tested whether AGEs-induced activation of $\mathrm{ENaC}$ is mediated by PTEN or PI3K. Consistent with our previous findings [12], ENaC $P_{\mathrm{O}}$ was increased by $\sim 70 \%$ (from $0.30 \pm 0.03$ to $0.51 \pm 0.03 ; n=6 ; P<0.05)$ in A6 cells treated with a specific PTEN inhibitor, $\mathrm{BPV}_{(\text {pic })}$ (Figure 5(a)). In AGEs-pretreated cells, ENaC $P_{O}$ was also significantly elevated by $\mathrm{BPV}_{(\mathrm{pic})}$, from $0.50 \pm 0.02$ to $0.67 \pm 0.04(n=6 ; P<$ 0.05), but with a less extent ( 34\%) (Figure 5(b)). LY294002, a PI3K inhibitor, significantly decreased $\mathrm{ENaC} P_{\mathrm{O}}$ in untreated control A6 cells (from $0.29 \pm 0.02$ to $0.23 \pm 0.04$, reduced $\sim 21 \%$; $n=6 ; P<0.01$ ) (Figure 5(c)). However, in AGEs-pretreated cells, LY294002 reduced ENaC $P_{O}$ by $\sim 46 \%$ ( $0.46 \pm 0.03$ versus $0.25 \pm 0.04 ; n=6 ; P<0.01$ ) (Figure 5(d)). These data together suggest that the inhibition of TPEN and PI3K is involved in AGEs-induced activation of $\mathrm{ENaC}$ in $\mathrm{A} 6$ cells. 


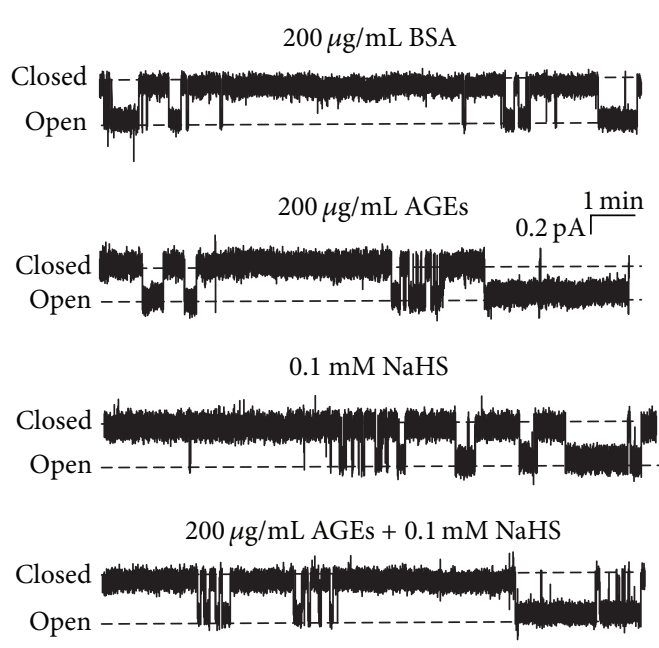

(a)

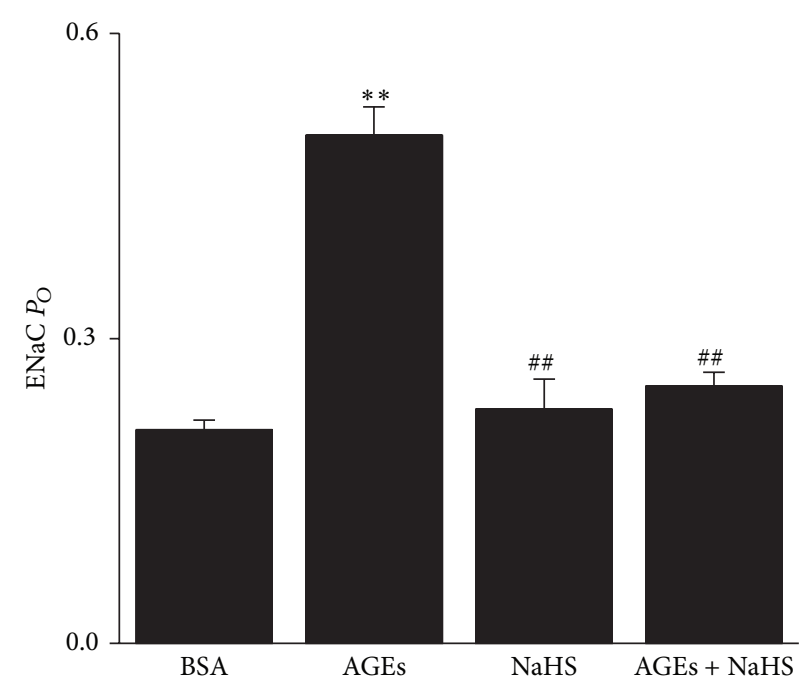

(b)

Figure 1: AGEs-induced activation of ENaC is reversed by $0.1 \mathrm{mMNaHS}$ in A6 cells. (a) The representative ENaC single-channel current recorded from A6 cells, respectively, treated with basolateral $200 \mu \mathrm{g} / \mathrm{mL}$ BSA (control; top trace), basolateral $200 \mu \mathrm{g} / \mathrm{mL}$ AGEs, apical $0.1 \mathrm{mM} \mathrm{NaHS}$, and basolateral $200 \mu \mathrm{g} / \mathrm{mL}$ AGEs + apical $0.1 \mathrm{mM} \mathrm{NaHS}$ (bottom trace) for $24 \mathrm{~h}$. (b) Summary plot shows that AGEs treatment significantly increased $\mathrm{ENaC} P_{\mathrm{O}}$, which was reversed by $\mathrm{H}_{2} \mathrm{~S}$ treatment $(n=10$ for each individual experimental set; $* *$ indicates $P<0.01$ compared to control; \#\# indicates $P<0.01$ compared to AGEs treated cells).

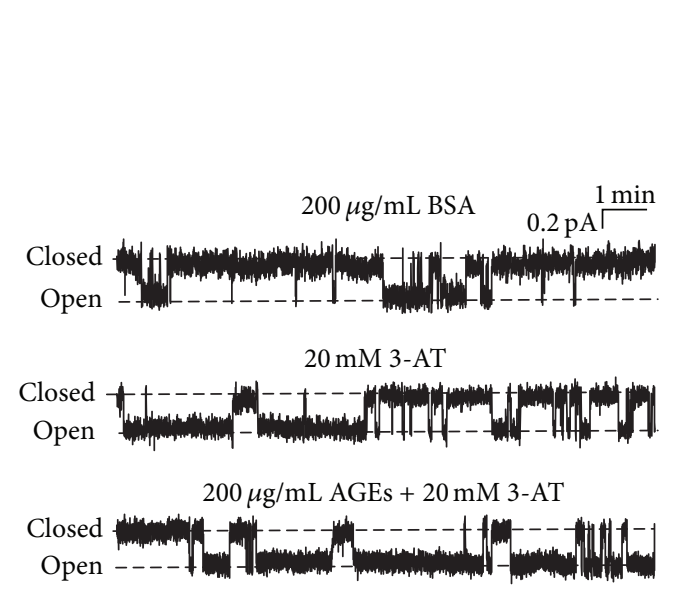

(a)

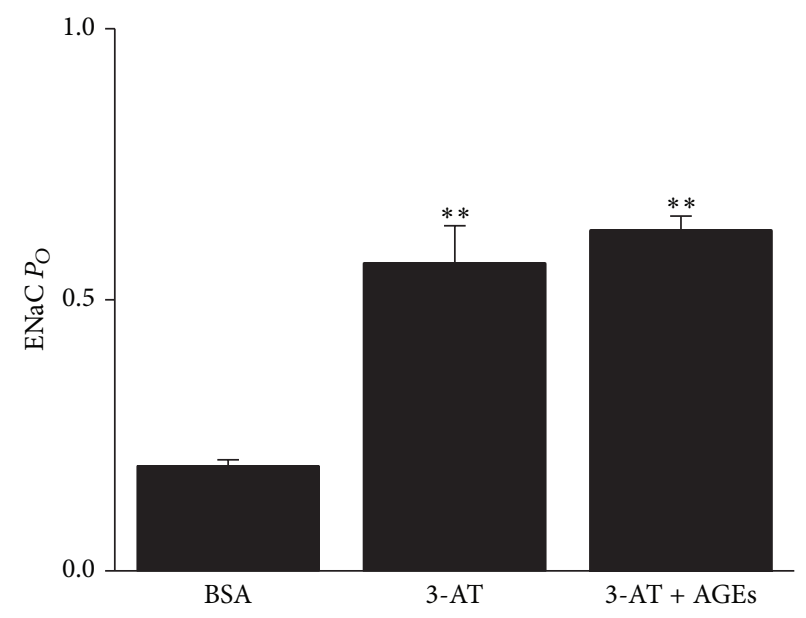

(b)

Figure 2: 3-Aminotriazole (3-AT) mimics the effect of AGEs on ENaC $P_{\mathrm{O}}$. (a) The representative single-channel currents of ENaC recorded under control conditions (basolateral $200 \mu \mathrm{g} / \mathrm{mL}$ BSA for $24 \mathrm{~h}$; top), after apical $20 \mathrm{mM}$ 3-AT treatment for 30 min (middle), or after $24 \mathrm{~h}$ AGE treatment followed by treatment with apical $20 \mathrm{mM}$ 3-AT for $30 \mathrm{~min}$ (bottom). (b) Summary plots show that ENaC $P_{O}$ was significantly, respectively, increased after $20 \mathrm{mM} 3$-AT treatment $(n=10$ for control and $n=9$ for 3-AT group; $* *$ indicates $P<0.01$ compared to control). Addition of 3-AT to AGEs did not further increase ENaC $P_{O}$ compared to 3-AT alone ( $n=9$ for AGEs +3 -AT group; $P>0.05$ ).

3.6. Metabolic Memory Effects of AGEs on ENaC Activity. Since AGEs potently upregulate ENaC activity, we hypothesized that AGEs may exert a sustained stimulatory effect on $\mathrm{ENaC}$ after withdrawing AGEs, which is called "metabolic memory." To test this hypothesis, we firstly treated the A6 cells with the medium containing BSA for $24 \mathrm{~h}$ and then removed BSA from the medium to continuously culture the cells for $72 \mathrm{~h}$. We also cultured the cells with a medium containing AGEs for $24 \mathrm{~h}$ and then removed AGEs from the medium
(AGEs-free) followed by continuously culturing these cells for another $72 \mathrm{~h}$. As seen in Figure 6, removal of BSA did not affect ENaC $P_{O}$ (Figures 6(a) and 6(c)). Consistent with previous results, AGEs significantly increased ENaC $P_{\mathrm{O}}(0.50 \pm 0.03 ; n=7)$; interestingly, $\mathrm{ENaC} P_{\mathrm{O}}$ remained at the similar high levels in the cells $72 \mathrm{~h}$ after removal of AGEs $(n=10 ; P>0.1$ ) (Figures 6(b) and 6(c)). These results suggest that $\mathrm{AGEs}$ regulate $\mathrm{ENaC}$ with metabolic memory. 


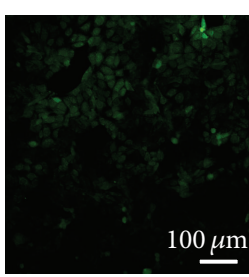

Control

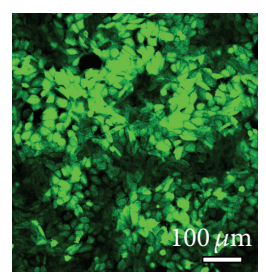

AGEs

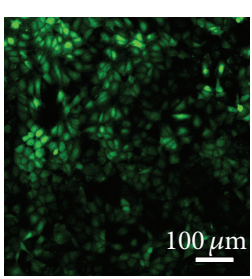

AGEs + NaHS

(a)

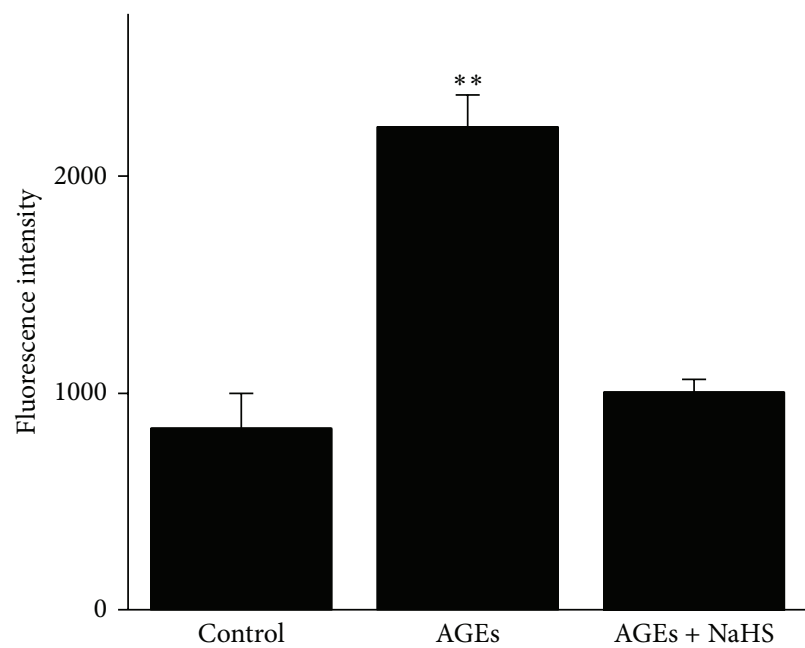

(c)

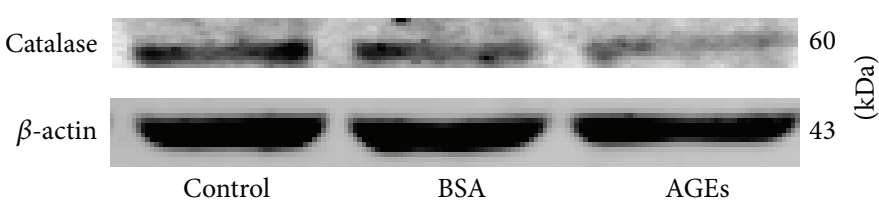

(e)

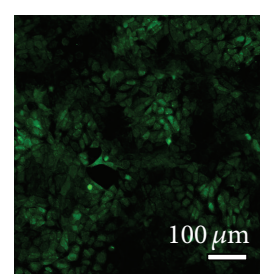

Control

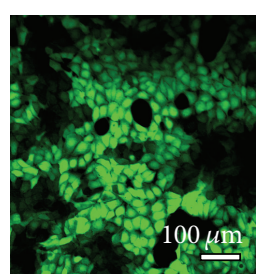

3-AT

(b)

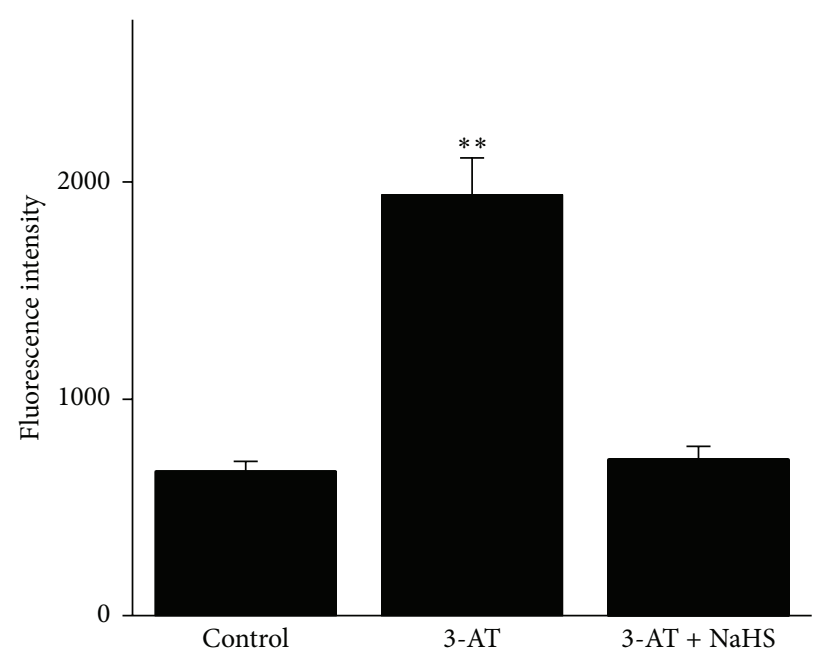

(d)
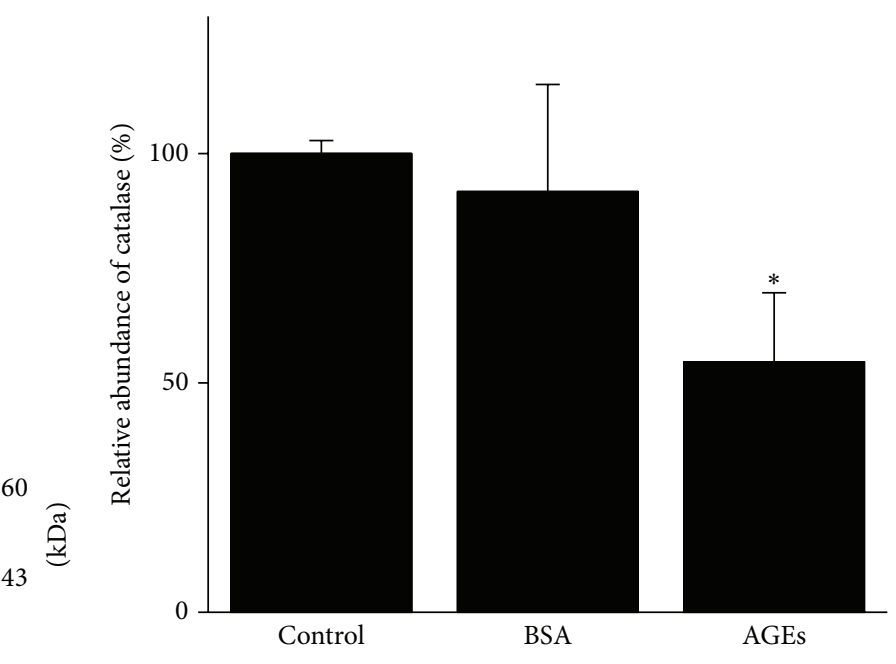

(f)

FIGURE 3: $\mathrm{H}_{2} \mathrm{~S}$ ameliorates AGE- or 3-AT-elicited oxidative stress and AGEs reduce catalase expression in A6 cells. (a) The left image shows that there was a residual level of intracellular ROS under control condition; the middle image shows a significant increase in intracellular ROS upon application of basolateral $200 \mu \mathrm{g} / \mathrm{mL}$ AGEs; the right image shows that the AGE-induced increase in intracellular ROS was abolished by $0.1 \mathrm{mM} \mathrm{NaHS}$ treatment. (b) The left image shows that there was a residual level of intracellular ROS under control conditions; the middle image shows a significant increase in intracellular ROS upon application of apical $20 \mathrm{mM}$ 3-AT; the right image shows that the 3-AT-induced increase in intracellular ROS was also abolished by $0.1 \mathrm{mM} \mathrm{NaHS}$ treatment. (c) and (d) Summarized bar graphs show the mean fluorescence intensities under indicated experimental conditions $(n=7$ for each experimental condition; $* *$ indicates $P<0.01$ compared to control). (e) and (f) Western blot demonstrating that expression levels of catalase were suppressed by AGEs $(n=6, *$ represents $P<0.05$ compared to control). 


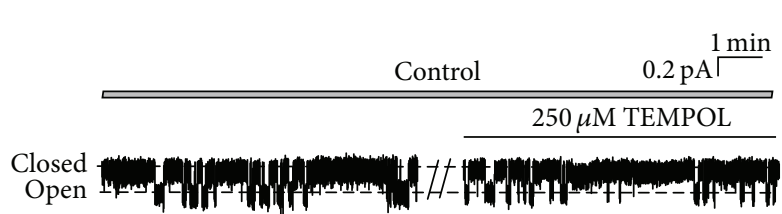

(a)

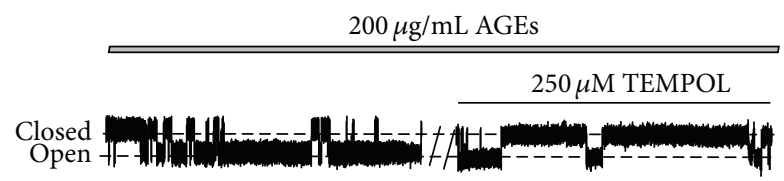

(b)

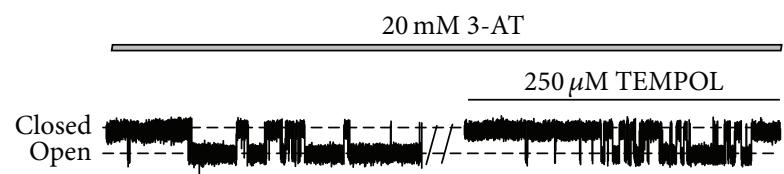

(c)
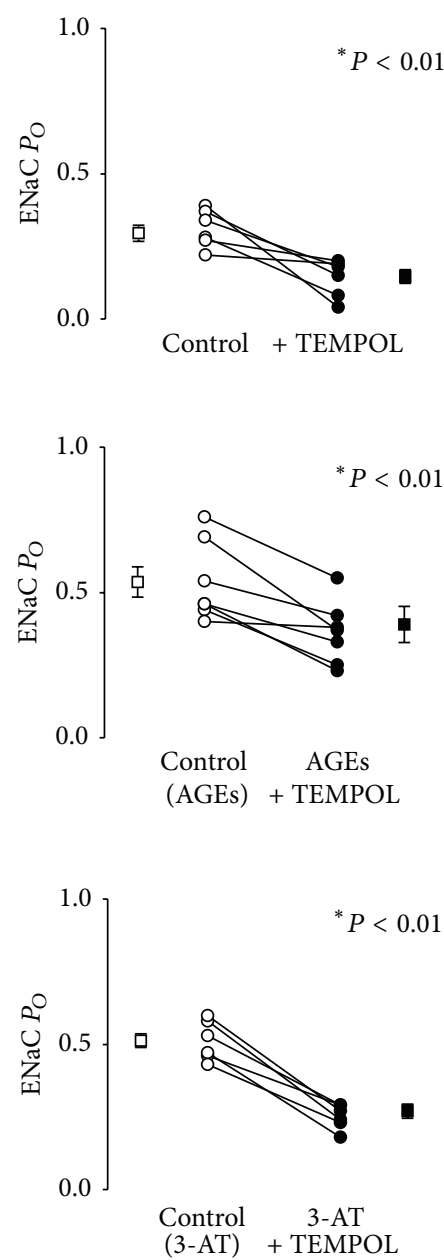

FIGURE 4: TEMPOL abolishes the effects of AGEs and 3-AT on ENaC activity. (a) ROS extraction by $250 \mu \mathrm{M}$ TEMPOL significantly decreased $\mathrm{ENaC} P_{\mathrm{O}}(n=6$ paired experiments; $*$ represents $P<0.01)$. (b) and (c) TEMPOL significantly reduced ENaC activity in cells pretreated with $200 \mu \mathrm{g} / \mathrm{mL}$ AGEs (b) or in the cells pretreated with $20 \mathrm{mM} \mathrm{3-AT} \mathrm{(c)}(n=7$ paired experiments; $*$ represents $P<0.01)$.

\section{Discussion}

Our major findings in this study are as follows: (1) AGEs stimulate $\mathrm{ENaC}$ by elevating intracellular ROS via inhibition of catalase; (2) NaHS reverses the effects of AGEs on ENaC activity by reducing AGEs-induced accumulation of intracellular ROS; (3) AGEs stimulate ENaC with "metabolic memory"; and (4) AGEs strongly activate ENaC through ROS/PTEN/PI3K singling pathways.

AGEs are produced by long-term challenge with high glucose and polypeptides. AGEs are the important pathogenic factors in diabetic nephropathy; however, almost all previous studies have focused on the mechanisms how AGEs take their effects on glomerular and vascular cells [23]. The effects of AGEs on fine sodium absorption in renal tubule cells, particularly in collecting ducts, have rarely been explored. It has previously been reported that circulating AGEs correspond to approximately $50 \mathrm{mg} / \mathrm{mL}$ of AGEs in diabetic patients [24]. Because the amount of AGEs decreases in the urine of diabetic patients, therefore we used Snapwell insert to culture
A6 cells in order to mimic the biological environment. We then applied AGEs to the basolateral membrane, where renal collecting tubules should be exposed to high concentration of AGEs in vivo. Because AGEs may be concentrated in renal tissues in vivo and the corresponding levels of AGEs in vitro have not been conclusively determined, we examined the effects of a variety concentration of AGEs (up to $500 \mathrm{mg} / \mathrm{mL}$ ) on cellular viability. Our data show that incubation of A6 cells with AGEs (up to $500 \mu \mathrm{g} / \mathrm{mL}$ ) for $24 \mathrm{~h}$ did not affect cell viability (data not shown). Therefore, the effects of AGEs on ENaC should not be due to nonspecific effects on cell viability because in all the experiments A6 cells were treated with only $200 \mu \mathrm{g} / \mathrm{mL}$ AGEs. Instead, our results show that AGEs stimulate $\mathrm{ENaC}$ in A6 cells through catalase inhibition and subsequently an increase in intracellular ROS levels. We propose that catalase is a major player, because 3-AT, a catalase inhibitor, mimics the effects of AGEs on $\mathrm{ENaC}$ activity and intracellular ROS levels, albeit 3-AT at a concentration of $20 \mathrm{mM}$ may lead to saturated increase in $\mathrm{ENaC}$ activity; this might result in a possibility that there 


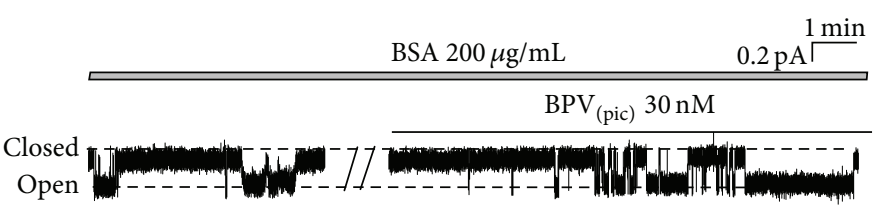

(a)

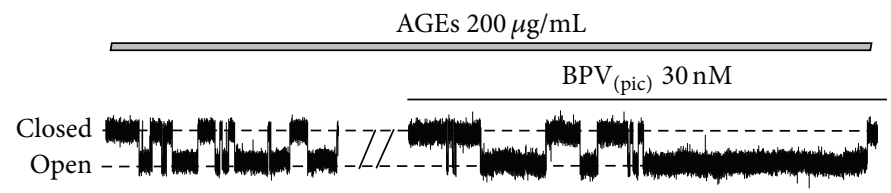

(b)

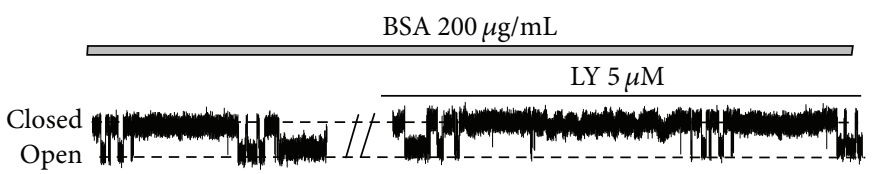

(c)

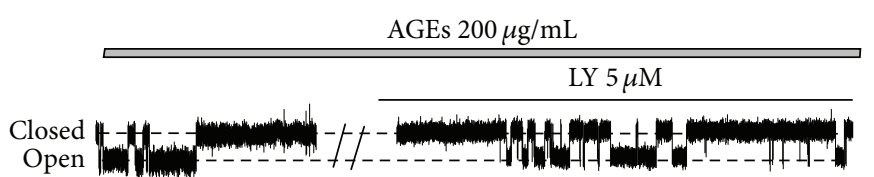

(d)
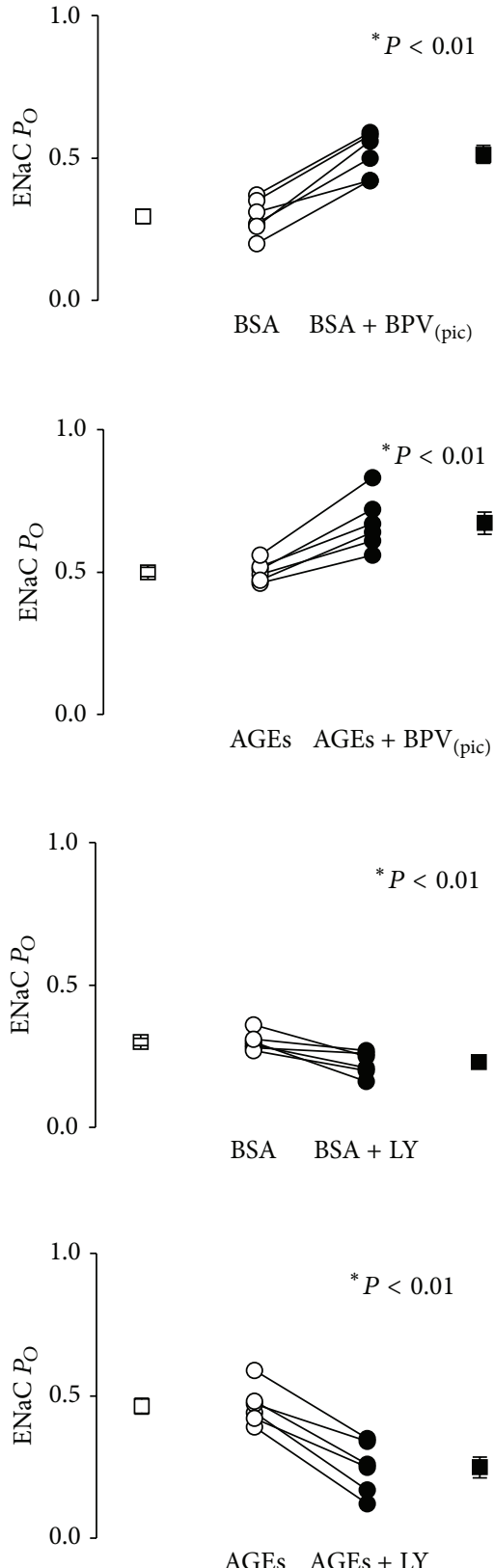

AGEs AGEs + LY

FIGURE 5: AGEs activate ENaC via PI3K and PTEN signaling pathways. (a) and (b) ENaC activity in A6 cells treated either with basolateral $200 \mu \mathrm{g} / \mathrm{mL}$ BSA or with basolateral $200 \mu \mathrm{g} / \mathrm{mL}$ AGEs, before and after addition of $30 \mathrm{nM} \mathrm{BPV}$ (pic) to the apical bath. (c) and (d) ENaC activity in A6 cells treated as in (a) and (b), before and after addition of $5 \mu \mathrm{M}$ LY294002 to the apical bath; the data show that a PI3K inhibitor, LY294002, significantly inhibits ENaC activities under control condition and in the presence of AGEs. Four breaks between the traces indicate 20 min omitted recording periods. Summarized $P_{O}$ of ENaC before and after application of each reagent were shown on the right. $n=6$ paired experiments. $*$ indicates $P<0.01$.

is a catalase-independent effect of AGEs on ENaC activity. However, our data show that AGEs suppress the expression levels of catalase and that in AGEs treated cells 3-AT was no longer able to further activate $\mathrm{ENaC}$. We also propose that ROS plays a critical role in downstream catalase, because, in the presence of ROS scavenger, TEMPOL, AGEs- and 3-AT-induced activation of $\mathrm{ENaC}$ were almost completely abolished. Our studies clearly suggest that ROS mediates the
AGEs-induced activation of $\mathrm{ENaC}$ in $\mathrm{A} 6$ cells. Our results are also consistent with previous studies, where the amiloridesensitive short-circuit currents across A6 cell monolayer were significantly reduced by extraction of intracellular ROS with TEMPOL [25].

It is well documented that oxidative stress is a primary cause of diabetes-induced kidney injury, which may be involved in diabetic hypertension $[1,2]$. Recently, we have 


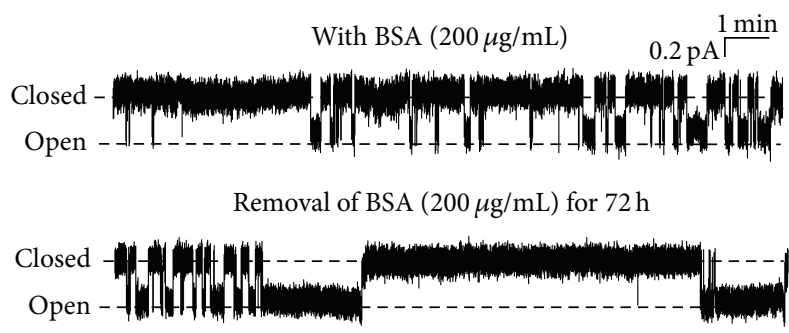

(a)

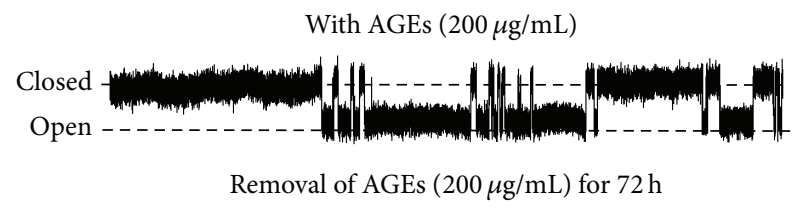

Closed

(b)

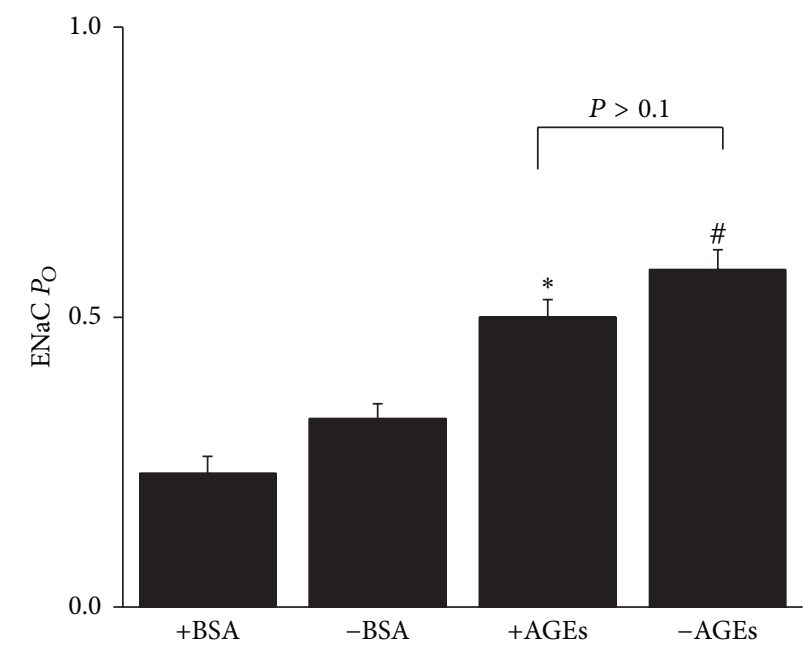

(c)

FIGURE 6: AGEs-induced aberrant activation of ENaC in A6 cells exerts "metabolic memory." (a) Representative ENaC single-channel currents recorded either from an A6 cell in the presence of basolateral $200 \mu \mathrm{g} / \mathrm{mL}$ BSA or from an A6 cell after removal of $200 \mu \mathrm{g} / \mathrm{mL} \mathrm{BSA} \mathrm{for} 72 \mathrm{~h}$. (b) Representative ENaC single-channel currents recorded either from an A6 cell in the presence of basolateral $200 \mu \mathrm{g} / \mathrm{mL}$ AGEs from an A6 cell after removal of $200 \mu \mathrm{g} / \mathrm{mL}$ AGEs for $72 \mathrm{~h}$. (c) Summarized bar graph shows that basolateral AGEs significantly increased ENaC $P_{O}$ and the ENaC $P_{O}$ remained at the same levels after removal of AGEs for $72 \mathrm{~h}(n=7-10$; $*$ and \#, resp., indicate $P<0.01)$.

shown that $\mathrm{H}_{2} \mathrm{O}_{2}$-induced increase in $\mathrm{ENaC}$ activity can be reversed by NaHS (a $\mathrm{H}_{2} \mathrm{~S}$ donor) in A6 cells [12]. $\mathrm{H}_{2} \mathrm{~S}$ is an endogenous gaseous mediator that exerts various physiological and pathophysiological effects in vivo, including antioxidative stress and anti-inflammatory response in heart, liver, kidney, and other organs [26-28]. It was reported that NaHS provided cytoprotection in human neuroblastoma cells exposed to D-galactose and that $\mathrm{H}_{2} \mathrm{~S}$ may have potential antiaging effects through a reduction of ROS and AGEs formation [29]. As an endogenous signaling molecule, $\mathrm{H}_{2} \mathrm{~S}$ can be as high as $0.1 \mathrm{mM}$ in human blood [30] or about $1.6 \mathrm{nmol} / \mathrm{mg}$ in intact rat kidneys [31]. Therefore, a final concentration of $0.1 \mathrm{mMNaHS}$ which was used in this study should represent the physiological concentrations, as we reported previously [12]. Our results show that AGEsinduced activation of ENaC and accumulation of intracellular ROS were completely reversed by $0.1 \mathrm{mM} \mathrm{NaHS}$. These results suggest that $\mathrm{H}_{2} \mathrm{~S}$ exerts a protective effect against elevation of intracellular ROS and ENaC activity induced by AGEs.

Our previous studies suggest that an increase in intercellular ROS leads to elevation of $\mathrm{PI}(3,4,5) \mathrm{P}_{3}$ near the apical compartment of A6 cells [12,13], which is known to stimulate $\mathrm{ENaC}[32,33]$. Since the levels of $\mathrm{PI}(3,4,5) \mathrm{P}_{3}$ near the apical compartment of A6 cells are governed by both PTEN and
PI3K $[12,13]$, we examined both PTEN and PI3K inhibitors on $\mathrm{ENaC}$ activity in the absence or in the presence of AGEs. Consistent with previous findings [12,13], it appears that both PTEN and PI3K are involved in the activation of ENaC by AGEs. Interestingly, it has been reported that there are reduced $\mathrm{H}_{2} \mathrm{~S}$ levels in diabetic rats and that $\mathrm{H}_{2} \mathrm{~S}$ can increase cellular $\mathrm{PI}(3,4,5) \mathrm{P}_{3}$ levels and can enhance glucose utilization in adipocytes by activating PI3K and inhibiting PTEN [34, 35]. Moreover, we have shown that in distal nephron epithelial cells increased intracellular ROS elevates $\mathrm{PI}(3,4,5) \mathrm{P}_{3}$ levels near the apical membrane compartment via PTEN/PI3K to stimulate $\mathrm{ENaC}[12,13]$. However, it would be difficult to determine whether PTEN and PI3K equally contribute to effects of AGEs on ENaC activity.

Finally, this study also provides an evidence for AGEs to stimulate $\mathrm{ENaC}$ via a metabolic memory phenomenon which occurs in the long-term progression of diabetic complications in kidney. This phenomenon describes a surprising persistence of the deleterious effects of high glucose even after hyperglycemia has been tightly controlled. This cellular memory phenomenon was revealed by large-scale multicenter clinical trials such as the Diabetes Control and Complications Trial (DCCT) and the Follow-Up Observational Epidemiology of Diabetes [5]. Interestingly, we found that 
the effect of AGEs on ENaC activity in A6 cells lasted, at least, for $72 \mathrm{~h}$ after removal of AGEs, suggesting that there is a metabolic memory phenomenon in $\mathrm{Na}^{+}$homeostasis. This metabolic memory may play an important role in sustaining activation of $\mathrm{ENaC}$, which accounts for the development of hypertension in diabetic patients.

\section{Conclusion}

AGEs significantly stimulate ENaC activity in A6 cells via inhibition of catalase and the effects of AGEs can be reversed by NaHS. Inhibition of catalase activity accounts for both oxidative stress induced by AGEs and elevation of $\mathrm{PI}(3,4,5) \mathrm{P}_{3}$ near the apical membrane compartment via PTEN/PI3K signaling pathways, thereby regulating ENaC activity. Finally, the effect of AGEs on ENaC activity exerts a metabolic memory phenomenon in A6 cells.

\section{Conflict of Interests}

The authors have no conflict of interests to declare.

\section{Authors' Contribution}

Qiushi Wang and Binlin Song contributed equally to this work.

\section{Acknowledgments}

This study was supported by the Key Project of Chinese National Program for Fundamental Research and Development (973 Program 2012CB517803, 2014CB542401 to Zhi-Ren Zhang), the National Natural Science Foundation of China (81070217, 81270340, and 81320108002 to Zhi-Ren Zhang), a grant from National Institutes of Health grant (R01 DK 100582 to He-Ping Ma), and a Research Project of Health and Family Planning Commission of Heilongjiang Province (2014-330 to Binlin Song).

\section{References}

[1] F. Persson, P. Rossing, P. Hovind et al., "Irbesartan treatment reduces biomarkers of inflammatory activity in patients with type 2 diabetes and microalbuminuria: an IRMA 2 substudy," Diabetes, vol. 55, no. 12, pp. 3550-3555, 2006.

[2] M. Portero-Otin, R. Pamplona, M. J. Bellmunt et al., "Advanced glycation end product precursors impair epidermal growth factor receptor signaling," Diabetes, vol. 51, no. 5, pp. 1535-1542, 2002.

[3] J. R. Sowers, M. Epstein, and E. D. Frohlich, "Diabetes, hypertension, and cardiovascular disease: an update," Hypertension, vol. 37, no. 4, pp. 1053-1059, 2001.

[4] E. D. Schleicher, E. Wagner, and A. G. Nerlich, "Increased accumulation of the glycoxidation product $\mathrm{N}(\varepsilon)$ - (carboxymethyl)lysine in human tissues in diabetes and aging," The Journal of Clinical Investigation, vol. 99, no. 3, pp. 457-468, 1997.

[5] D. M. Nathan, P. A. Cleary, J. Y. C. Backlund et al., "Intensive diabetes treatment and cardiovascular disease in patients with type 1 diabetes," The New England Journal of Medicine, vol. 353, no. 25, pp. 2643-2653, 2005.

[6] D. G. Warnock, "The epithelial sodium channel in hypertension," Current Hypertension Reports, vol. 1, no. 2, pp. 158-163, 1999.

[7] C. T. Chang, M. S. Wu, Y. C. Tian et al., "Enhancement of epithelial sodium channel expression in renal cortical collecting ducts cells by advanced glycation end products," Nephrology Dialysis Transplantation, vol. 22, no. 3, pp. 722-731, 2007.

[8] Y. Kimura and H. Kimura, "Hydrogen sulfide protects neurons from oxidative stress," The FASEB Journal, vol. 18, no. 10, pp. 1165-1167, 2004.

[9] X.-Q. Tang, C.-T. Yang, J. Chen et al., "Effect of hydrogen sulphide on $\beta$-amyloid-induced damage in PC12 cells," Clinical and Experimental Pharmacology and Physiology, vol. 35, no. 2, pp. 180-186, 2008.

[10] M. Lu, L.-F. Hu, G. Hu, and J.-S. Bian, "Hydrogen sulfide protects astrocytes against $\mathrm{H}_{2} \mathrm{O}_{2}$-induced neural injury via enhancing glutamate uptake," Free Radical Biology \& Medicine, vol. 45, no. 12, pp. 1705-1713, 2008.

[11] M. Whiteman, J. S. Armstrong, S. H. Chu et al., "The novel neuromodulator hydrogen sulfide: an endogenous peroxynitrite 'scavenger'?" Journal of Neurochemistry, vol. 90, no. 3, pp. 765-768, 2004.

[12] J. Zhang, S. Chen, H. Liu et al., "Hydrogen sulfide prevents hydrogen peroxide-induced activation of epithelial sodium channel through a PTEN/PI $(3,4,5) \mathrm{P} 3$ dependent pathway," PLoS ONE, vol. 8, no. 5, Article ID e64304, 2013.

[13] H.-P. Ma, "Hydrogen peroxide stimulates the epithelial sodium channel through a phosphatidylinositide 3-kinase-dependent pathway," The Journal of Biological Chemistry, vol. 286, no. 37, pp. 32444-32453, 2011.

[14] J. Wang, Z. R. Zhang, C. F. Chou, Y.-Y. Liang, Y. Gu, and M. He-Ping, "Cyclosporine stimulates the renal epithelial sodium channel by elevating cholesterol," The American Journal of Physiology-Renal Physiology, vol. 296, no. 2, pp. F284-F290, 2009.

[15] Z. R. Zhang, C. F. Chou, J. Wang, Y. Y. Liang, and H. P. $\mathrm{Ma}$, "Anionic phospholipids differentially regulate the epithelial sodium channel $(\mathrm{ENaC})$ by interacting with alpha, beta, and gamma ENaC subunits," Pflugers Archiv European Journal of Physiology, vol. 459, no. 3, pp. 377-387, 2010.

[16] N. E. Taylor, P. Glocka, M. Liang, and A. W. Cowley Jr., "NADPH oxidase in the renal medulla causes oxidative stress and contributes to salt-sensitive hypertension in Dahl S rats," Hypertension, vol. 47, no. 4, pp. 692-698, 2006.

[17] K. Shatalin, E. Shatalina, A. Mironov, and E. Nudler, " $\mathrm{H}_{2} \mathrm{~S}$ : a universal defense against antibiotics in bacteria," Science, vol. 334, no. 6058, pp. 986-990, 2011.

[18] B.-H. Chen, D.-Y. Jiang, and L.-S. Tang, "Advanced glycation end-products induce apoptosis involving the signaling pathways of oxidative stress in bovine retinal pericytes," Life Sciences, vol. 79, no. 11, pp. 1040-1048, 2006.

[19] Y. Auyeung, R. E. Sievers, D. Weng, V. Barbosa, and C. L. Wolfe, "Catalase inhibition with 3-amino-1,2,4-triazole does not abolish infarct size reduction in heat-shocked rats," Circulation, vol. 92, no. 11, pp. 3318-3322, 1995.

[20] Y. Hu, X. Chen, T.-T. Pan et al., "Cardioprotection induced by hydrogen sulfide preconditioning involves activation of ERK and PI3K/Akt pathways," Pflügers Archiv, vol. 455, no. 4, pp. 607-616, 2008 
[21] D. Johansen, K. Ytrehus, and G. F. Baxter, "Exogenous hydrogen sulfide $\left(\mathrm{H}_{2} \mathrm{~S}\right)$ protects against regional myocardial ischemiareperfusion injury-evidence for a role of KATP channels," Basic Research in Cardiology, vol. 101, no. 1, pp. 53-60, 2006.

[22] A. Gericke, M. Munson, and A. H. Ross, "Regulation of the PTEN phosphatase," Gene, vol. 374, no. 1-2, pp. 1-9, 2006.

[23] W. Kim, B. I. Hudson, B. Moser et al., "Receptor for advanced glycation end products and its ligands: a journey from the complications of diabetes to its pathogenesis," Annals of the New York Academy of Sciences, vol. 1043, pp. 553-561, 2005.

[24] A. Vahlquist, L. Rask, P. A. Peterson, and T. Berg, "The concentrations of retinol binding protein, prealbumin, and transferrin in the sera of newly delivered mothers and children of various ages," Scandinavian Journal of Clinical and Laboratory Investigation, vol. 35, no. 6, pp. 569-575, 1975.

[25] H.-F. Bao, J. Z. Song, B. J. Duke, H.-P. Ma, D. D. Denson, and D. C. Eaton, "Ethanol stimulates epithelial sodium channels by elevating reactive oxygen species," American Journal of Physiology-Cell Physiology, vol. 303, no. 11, pp. C1129-C1138, 2012.

[26] P. Tripatara, N. S. A. Patel, V. Brancaleone et al., "Characterisation of cystathionine gamma-lyase/hydrogen sulphide pathway in ischaemia/reperfusion injury of the mouse kidney: an in vivo study," European Journal of Pharmacology, vol. 606, no. 1-3, pp. 205-209, 2009.

[27] S. Fiorucci, E. Antonelli, A. Mencarelli et al., "The third gas: $\mathrm{H}_{2} \mathrm{~S}$ regulates perfusion pressure in both the isolated and perfused normal rat liver and in cirrhosis," Hepatology, vol. 42, no. 3, pp. 539-548, 2005.

[28] J.-S. Bian, Q. C. Yong, T.-T. Pan et al., "Role of hydrogen sulfide in the cardioprotection caused by ischemic preconditioning in the rat heart and cardiac myocytes," Journal of Pharmacology and Experimental Therapeutics, vol. 316, no. 2, pp. 670-678, 2006.

[29] Y. Y. Liu, B. V. Nagpure, P. T. H. Wong, and J. S. Bian, "Hydrogen sulfide protects SH-SY5Y neuronal cells against d-galactose induced cell injury by suppression of advanced glycation end products formation and oxidative stress," Neurochemistry International, vol. 62, no. 5, pp. 603-609, 2013.

[30] S. K. Jain, R. Bull, J. L. Rains et al., "Low levels of hydrogen sulfide in the blood of diabetes patients and streptozotocintreated rats causes vascular inflammation?" Antioxidants and Redox Signaling, vol. 12, no. 11, pp. 1333-1338, 2010.

[31] Z. Xu, G. Prathapasinghe, N. Wu, S.-Y. Hwang, Y. L. Siow, and O. Karmin, "Ischemia-reperfusion reduces cystathionine- $\beta$ synthase-mediated hydrogen sulfide generation in the kidney," The American Journal of Physiology - Renal Physiology, vol. 297, no. 1, pp. F27-F35, 2009.

[32] O. Pochynyuk, Q. Tong, A. Staruschenko, and J. D. Stockand, "Binding and direct activation of the epithelial $\mathrm{Na}^{+}$channel (ENaC) by phosphatidylinositides," Journal of Physiology, vol. 580, no. 2, pp. 365-372, 2007.

[33] O. Pochynyuk, Q. Tong, A. Staruschenko, H.-P. Ma, and J. D. Stockand, "Regulation of the epithelial $\mathrm{Na}^{+}$channel (ENaC) by phosphatidylinositides," American Journal of Physiology-Renal Physiology, vol. 290, no. 5, pp. F949-F957, 2006.

[34] P. Manna and S. K. Jain, "Decreased hepatic phosphatidylinositol-3,4,5-triphosphate (PIP3) levels and impaired glucose homeostasis in type 1 and type 2 diabetic rats," Cellular Physiology and Biochemistry, vol. 30, no. 6, pp. 1363-1370, 2012.

[35] P. Manna and S. K. Jain, "Hydrogen sulfide and L-cysteine increase phosphatidylinositol 3,4,5-trisphosphate (PIP3) and glucose utilization by inhibiting phosphatase and tensin homolog (PTEN) protein and activating phosphoinositide 3kinase (PI3K)/serine/threonine protein kinase (AKT)/protein kinase Czeta/lambda (PKCzeta/lambda) in 3T311 adipocytes," Journal of Biological Chemistry, vol. 286, no. 46, pp. 3984839859, 2011. 


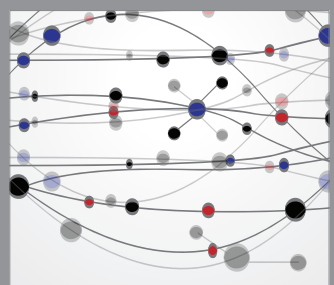

The Scientific World Journal
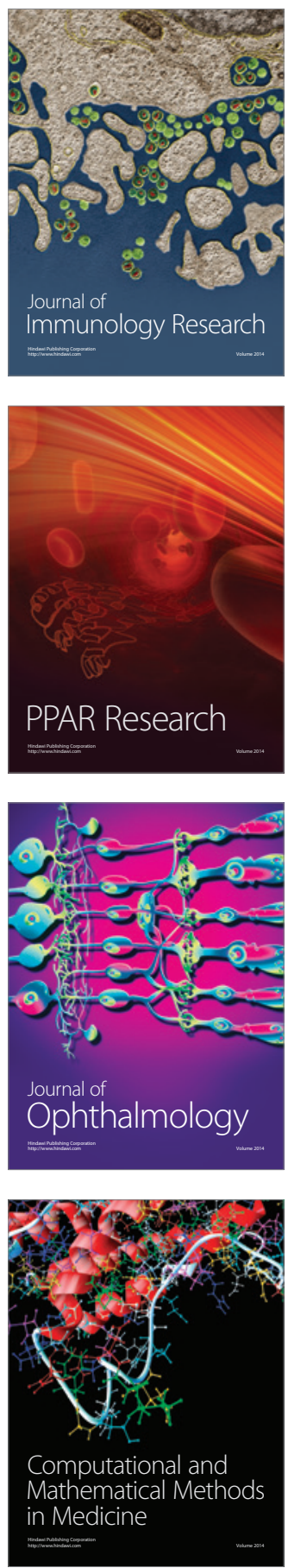

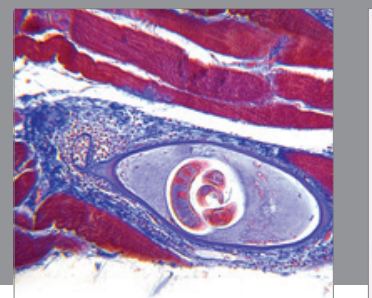

Gastroenterology

Research and Practice
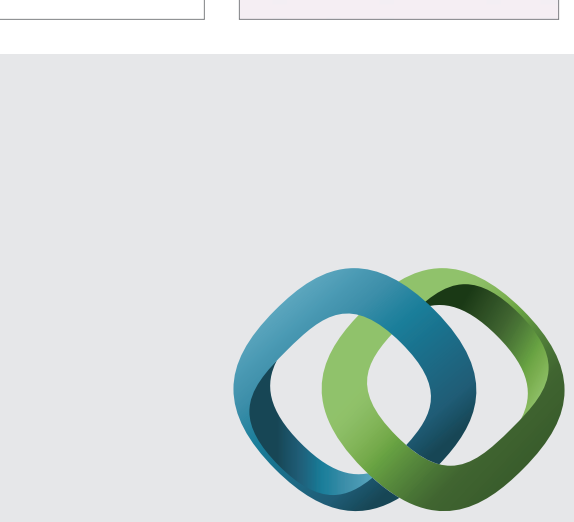

\section{Hindawi}

Submit your manuscripts at

http://www.hindawi.com
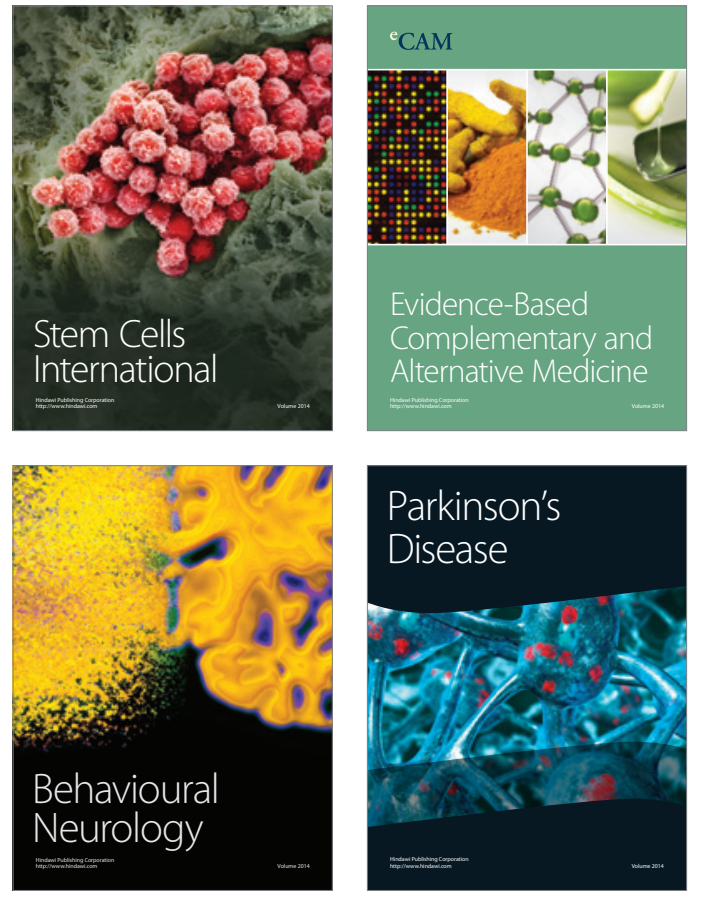
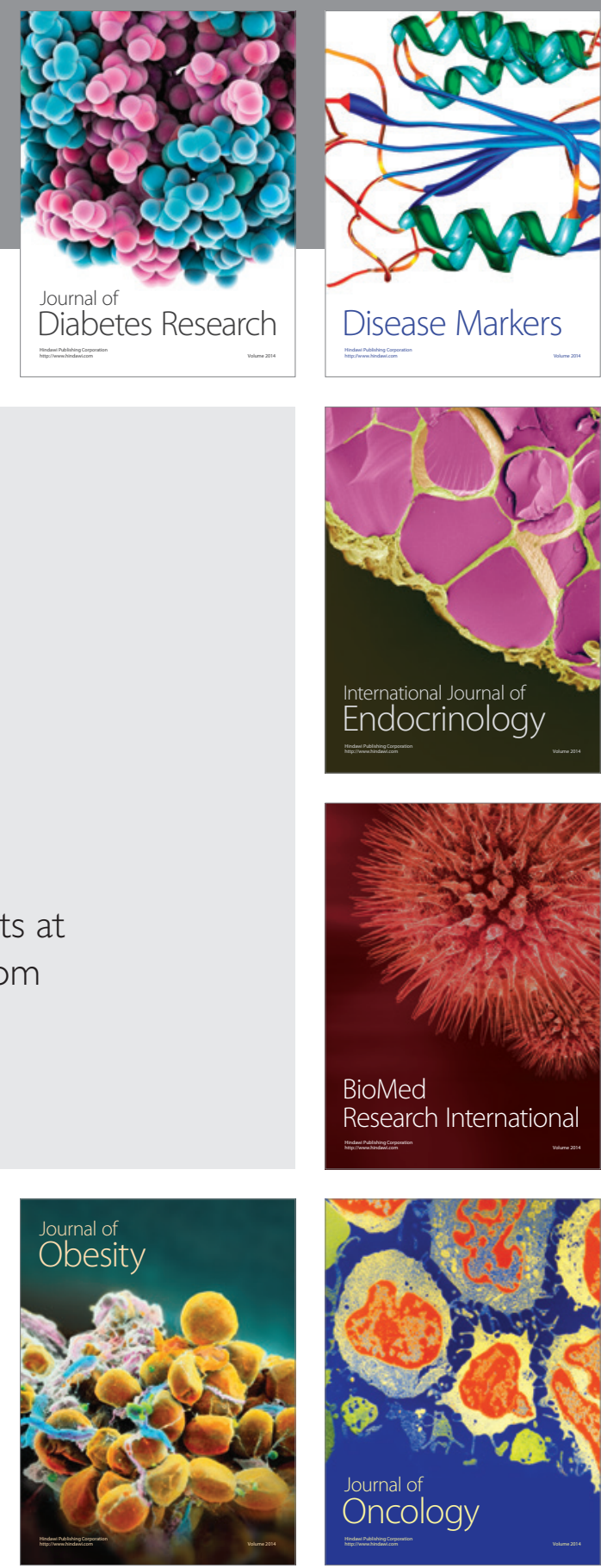

Disease Markers
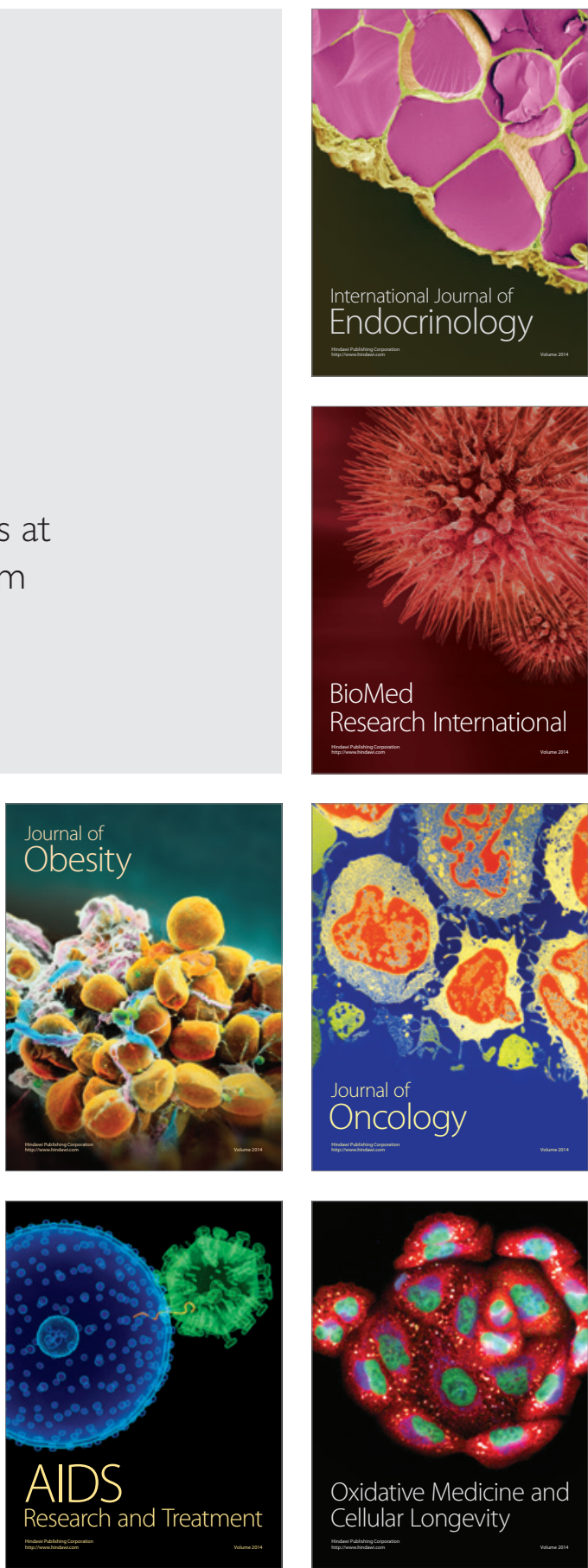